\title{
Sensitivity Analysis of an Advanced Transmission Measurement Method for Thermal Neutrons Absorbers Detection in Irradiated Beryllium.
}

\author{
Małgorzata Wróblewska ${ }^{\mathbf{a}, \mathbf{b}}$, David Blanchet ${ }^{\mathbf{b}}$, Abdallah Lyoussi ${ }^{\mathbf{b}}$, Patrick Blaise ${ }^{\mathbf{c}}$, \\ Zuzanna Marcinkowska ${ }^{a}$, Jacek Jagielski ${ }^{a}$, Agnieszka Boettcher ${ }^{\mathrm{a}}$ \\ a NCBJ 05-400 Otwock-Świerk, Poland \\ ${ }^{b}$ CEA Cadarache, DES/IRESNE/DER, F-13108 Saint Paul lez Durance, France \\ ${ }^{\text {c } C E A ~ S a c l a y, ~ D E S / E C / D S E, ~ F-91191 ~ G i f-s u r-Y v e t t e ~, ~ F r a n c e ~}$ \\ Malgorzata.wroblewska@ncbj.gov.pl
}

\begin{abstract}
This paper presents an advanced optimization analysis of the newly developed transmission measurement method conducted in the MARIA MTR reactor for thermal neutrons absorbers estimation in irradiated beryllium elements. Several neutron sources in combination with various thermal neutron detectors are investigated, along with the optimization of the moderating polyethylene layer to improve the signal to background ratio. It was concluded that the use of ${ }^{239} \mathrm{PuBe}$ or ${ }^{241} \mathrm{AmB}$ neutron source with polyethylene of $0.95 \mathrm{~g} / \mathrm{cm}^{3}$ density and $\sim 4.5 \mathrm{~cm}$ thickness, as well as either ${ }^{235} \mathbf{U}$ lined fission chamber or $\mathbf{B F}_{3}$ detectors are meeting the requirements for the use in the experiment.
\end{abstract}

Keywords - Transmission measurements, Sensitivity analysis, neutron sources, thermal neutron detectors, beryllium

I. INTRODUCTION

Experience in Material Testing Reactors (MTR) operating with beryllium shows important changes in this material properties, under the neutrons exposure [1-3]. Two main effects observed are mechanical damage and neutronic properties worsening [4,5]. The last effect is related to accumulation of thermal neutron absorbers (so-called poisons), induced by fast neutrons through $(n, \alpha)$ reaction on ${ }^{9} \mathrm{Be}[6,7]$.

A newly developed experimental method allows for inferring the actual build-up of absorbers in beryllium element from the transmission and absorption measurement of thermal neutrons in beryllium moderator block element of the MARIA pool type, material testing reactor, located in Poland $[8,9]$.

The experimental setup is composed of a neutron transmission source, a neutron moderator and a neutron detector, mounted on a bench with a beryllium sample placed between the source and the detector. The moderator used to thermalize the neutron source is a High Density Polyethylene (HDPE). The conical shape of the beryllium blocks contributes to uneven axial neutron flux distribution in the core. In order to perform measurements, both neutron source and detector move simultaneously along the block. A nonirradiated beryllium block constitutes the reference point. Comparing measurement results of an irradiated beryllium block to the reference results allows evaluating thermal neutrons absorbed in the irradiated beryllium.

A parametric analysis has been performed to optimize the setup and ensure qualitative experiments. All the steps of the experiment were simulated with the SERPENT2 [10] MonteCarlo code, using the JEFF3.1.1 [11] nuclear data library.

Several neutron sources were considered in this study: ${ }^{241} \mathrm{AmBe},{ }^{241} \mathrm{AmB},{ }^{239} \mathrm{PuBe}$, SbBe, ${ }^{252} \mathrm{Cf}$. The most commonly used detectors to measure thermal neutrons that were considered here are: fission chamber with ${ }^{235} \mathrm{U}$ neutron converter deposit, ${ }^{3} \mathrm{He}$ detector, ${ }^{10} \mathrm{~B}$ lined-detector and ${ }^{6} \mathrm{Li}$ scintillator.

\section{Neutron Transmission Experiment}

The scheme of the experimental setup for neutron transmission is presented in Fig. 1. It consists of a neutron source placed in an aluminium cylinder. A polyethylene half bushing is placed between the neutron source and the examined beryllium block. In the centre of the beryllium block is a slot, in which another aluminium tube containing the detector is placed. Both the neutron source and the detector move simultaneously along the block, with the minimum possible air gap between each element. The entire experimental setup is placed in a hot cell, to which beryllium elements are delivered through a system of pools connected with the reactor pool.

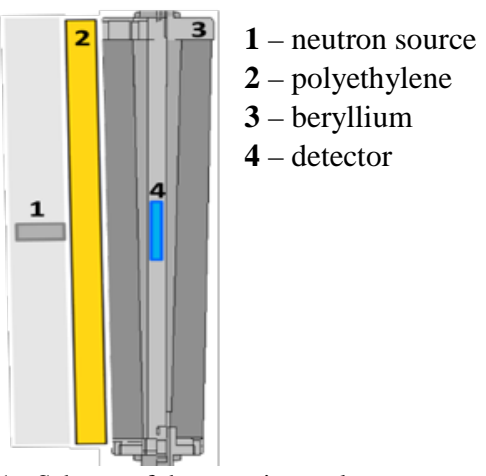

Fig. 1 - Scheme of the experimental setup

The experiment is based on the transmission method, where neutron beam from a chosen neutron source is transmitted through beryllium and induces reactions in the detector delivering counting rates. The ratio of neutrons passing through a nonirradiated beryllium block $\left(\mathrm{I}_{1}\right)$ to those passing through an irradiated beryllium block $\left(\mathrm{I}_{2}\right)$ and reaching the detector can be expressed with the transmission (T) function:

$$
T=\frac{I_{2}}{I_{1}}
$$

, where $I_{1}=I_{0} \cdot e^{-\Sigma_{1} x}, I_{2}=I_{0} \cdot e^{-\Sigma_{2} x}, \quad I_{0}$ is the incident neutron beam, beryllium thickness $\mathrm{x}, I_{1}$ neutron flux for nonirradiated and $\mathrm{I}_{2}$ neutron flux for irradiated beryllium. A full description of the methodology can be found in [12].

To optimise and allow for the most accurate measurements, the most suitable neutron source for the experiment should emit thermal neutrons, have narrow energy spectrum be accompanied by low or no gamma emission. The detector should have maximal sensitivity to thermal neutrons, small size, 
high detection efficiency and low gamma sensitivity. The polyethylene moderator is intended to thermalize incident neutrons.

\section{EXPERIMENTAL SETUP CONFIGURATION}

\section{A. Neutron source}

Isotopic neutron sources are commonly employed for the calibration of nuclear instrumentation. They are very practical due to their size and portability. Each source has a particular neutron energy distribution and strength (the emission rate). Regarding the reaction yielding the neutron production, one can distinguish three main types of sources:

a. ( $\boldsymbol{\alpha}, \mathbf{n})$ sources - alpha emitter is mixed with a low $\mathrm{Z}$ material. The ${ }^{9} \mathrm{Be}$ is most frequently used because of its relatively high neutron yield due to its low neutron binding energy $(\approx 1.67 \mathrm{MeV})$. Other target materials such as ${ }^{10} \mathrm{~B},{ }^{19} \mathrm{~F}{ }^{13} \mathrm{C}$ or ${ }^{7} \mathrm{Li}$ are also used [13]. The most common alpha emitters are ${ }^{241} \mathrm{Am},{ }^{238} \mathrm{Pu}$ and ${ }^{239} \mathrm{Pu}$

b. $(\gamma, \mathbf{n})$ sources - gamma emitter of specific gamma ray energy, higher than the Q-value (threshold energy) of $(\gamma, n)$ reaction of the target material [14]. The only two target materials with threshold energy below $4 \mathrm{MeV}$ are ${ }^{9} \mathrm{Be}$ $(\sim 1.67 \mathrm{MeV})$ and ${ }^{2} \mathrm{H}(\sim 2.23 \mathrm{MeV})[15]$.

c. Spontaneous fission neutron sources - contain isotopes that undergo a spontaneous fission; most commonly used are ${ }^{238} \mathrm{Pu},{ }^{242} \mathrm{Cm},{ }^{252} \mathrm{Cf}$.

Based on their characteristics given in Table 1, 5 neutron sources were chosen in the frame of the present study. The antimony source spectrum was calculated with iSourceC [16] code, whereas all the others are ISO calibration spectra [17]. All results presented in the following were obtained by MonteCarlo simulations, using the SERPENT code. These simulations enabled to tally the detectors' responses. Preliminary calculations were performed for a setup with manufacturer reference values, with a layer of nonborated polyethylene of $0.93 \mathrm{~g} / \mathrm{cm}^{3}$ density and $4.5 \mathrm{~cm}$ thickness, using the beryllium composition of a fresh MARIA reactor's element having density of $1.84 \mathrm{~g} / \mathrm{cm}^{3}$ [8].

TABLE 1 - CHOSEN PROPERTIES OF SELECTED NEUTRON SOURCES $[18,19]$.

\begin{tabular}{cccccc}
\hline \hline & $\mathbf{T}_{\mathbf{1} / \mathbf{2}}$ & $\overline{\mathbf{E}}_{\mathbf{n}}$ & $\begin{array}{c}\text { Emission } \\
\text { Rate }\end{array}$ & $\begin{array}{c}\text { Av. } \boldsymbol{\gamma} \\
\text { dose rate } \\
\mu \mathrm{Gy} / \mathrm{h} \text { at }\end{array}$ & $\overline{\mathbf{E}}_{\boldsymbol{\gamma}}$ \\
SourCE & $\mathrm{y}$ & $\mathrm{MeV}$ & $\mathrm{n} / \mathrm{s}$ & $\begin{array}{c}\mathrm{m} / \mathrm{GBq} \\
\mathrm{MeV}\end{array}$ \\
\hline${ }^{241} \mathbf{A m B e}$ & 433 & $\sim 4.2-5.0$ & $8 \cdot 10^{7}$ & 0.68 & 4.4 \\
${ }^{241} \mathbf{A m B}$ & 433 & $\sim 2.6$ & $8 \cdot 10^{7}$ & 1.75 & 2.8 \\
${ }^{239} \mathbf{P u B e}$ & 24000 & $\sim 4.2-5.0$ & $2 \cdot 10^{7}$ & 0.027 & \\
${ }^{\mathbf{1 2 4}} \mathbf{S b B e}$ & $60.4 \mathrm{~h}$ & $\sim 0.025$ & $2 \cdot 10^{7}$ & 270 & 1.7 \\
${ }^{252} \mathbf{C f}$ & 2.65 & $\sim 2.0-2.3$ & $5 \cdot 10^{7}$ & 140 & $0.2-1.8$ \\
\hline \hline
\end{tabular}

B. Polyethylene

As no pure thermal neutron source exists, the use of a polyethylene layer to maximize the number or thermal neutrons reaching beryllium was necessary. Polyethylene, thanks to its high content of hydrogen atoms, is a very good moderator. One can observe good thermalization of the neutron energy in Fig.
2 , when a $4.5 \mathrm{~cm}$ layer of polyethylene has been inserted in the setup of Fig. 1. The corresponding values of reaction rates in a fission chamber (with ${ }^{235} \mathrm{U}$ deposit) are given in the Table 2.
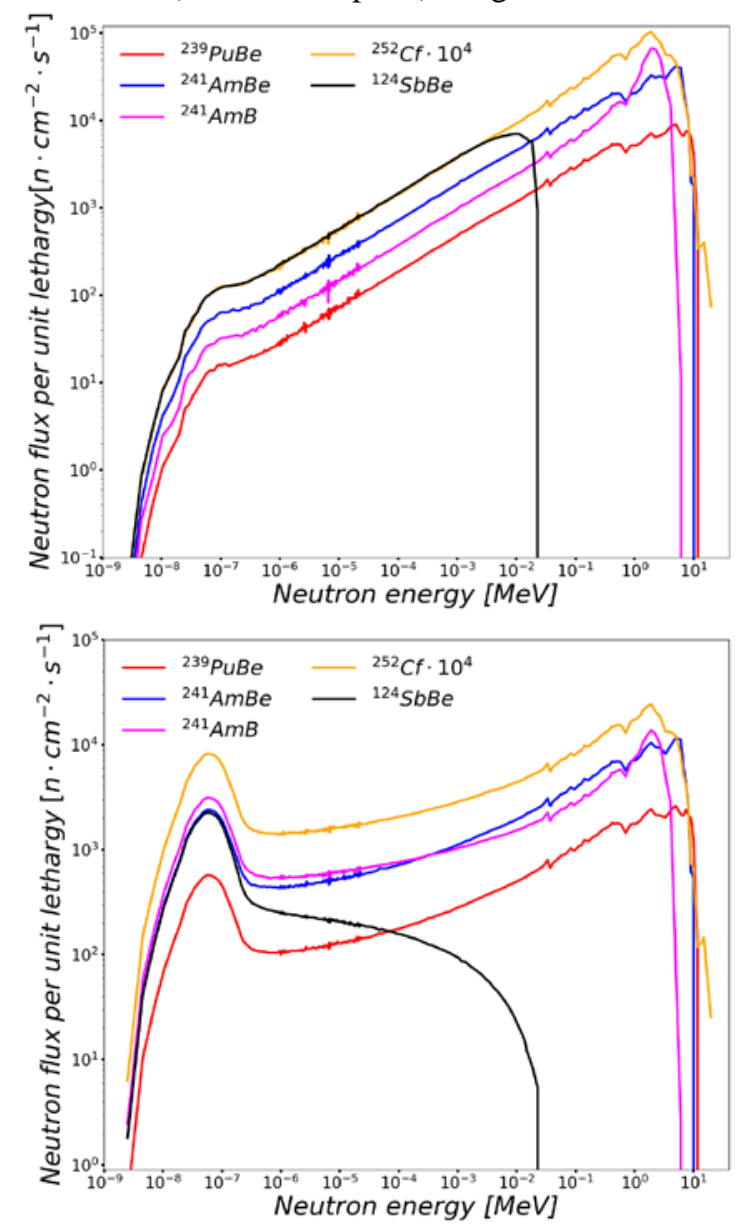

Fig. 2 - Un-moderated (up) and moderated with $4.5 \mathrm{~cm}$ of polyethylene (down) neutron source spectra at the detector's position.

TABLE 2 - REACTION RATES FOR DIFFERENT MODERATED (M - 4.5 CM)

AND NONMODERATED (NM) NEUTRON SOURCES.

\begin{tabular}{cccccc}
\multicolumn{6}{c}{ (MAXIMAL UNCERTAINTY $2 \Sigma=0.3 \%)}$. \\
\hline \hline & ${ }^{239} \mathrm{PuBe}$ & ${ }^{241} \mathrm{AmBe}$ & ${ }^{241} \mathrm{AmB}$ & ${ }^{252} \mathrm{Cf}$ & ${ }^{124} \mathrm{SbBe}$ \\
& & {$\left[\mathrm{s}^{-1}\right]$} & & \\
\hline NM. & $9.01 \mathrm{E}+04$ & $3.54 \mathrm{E}+05$ & $2.25 \mathrm{E}+05$ & $7.46 \mathrm{E}+09$ & $3.98 \mathrm{E}+05$ \\
$\mathrm{M}$ & $5.68 \mathrm{E}+05$ & $2.40 \mathrm{E}+06$ & $3.01 \mathrm{E}+06$ & $7.98 \mathrm{E}+10$ & $2.07 \mathrm{E}+06$ \\
\hline \hline
\end{tabular}

The most common densities of polyethylene range from $0.93 \mathrm{~g} / \mathrm{cm}^{3}$ to $0.95 \mathrm{~g} / \mathrm{cm}^{3}$ (HDPE - nonborated). Beryllium used for nuclear applications has $\sim 99 \%{ }^{9}$ Be purity and a density of $1.85 \mathrm{~g} / \mathrm{cm}^{3}$. Nonetheless, depending on the manufacturer, they can mainly differ in impurities content and beryllium grain size. One of the factors used to describe the amount of impurities in beryllium is the so-called danger factor denoted as $D_{f}$ and defined as:

$$
D_{f}=\frac{\widetilde{\Sigma_{a}}}{\Sigma_{a}}
$$


Where $\widetilde{\Sigma_{\mathrm{a}}}$ represents the effective cross section for thermal neutron absorption in beryllium with impurities, and $\Sigma_{a}$ is the effective cross section of pure beryllium [20].

For the current MARIA reactor's beryllium elements, $D_{f} \approx 1.94$, whereas for the BR2 beryllium elements, this value was estimated to $D_{f} \leq 1.75$ [20]. The high-density polyethylene has less branching than low-density polyethylene, which allows the polymer chains to pack closely together, resulting in a dense, crystalline material, hence higher neutron thermalization [21] and stronger signal in the detector compared to the same polyethylene thickness of lower density.

For ${ }^{239} \mathrm{PuBe}$ neutron source, the impact of polyethylene density in reaction rates is slightly more important than for ${ }^{241} \mathrm{AmBe}$. A similar trend is observed when the density of beryllium changes.

When choosing the neutron source, the optimal thickness of the polyethylene layer would slightly differ, depending on the neutron detector. An illustration of the signal in fission chamber for several polyethylene thicknesses and for selected neutron sources is presented in Fig. 3

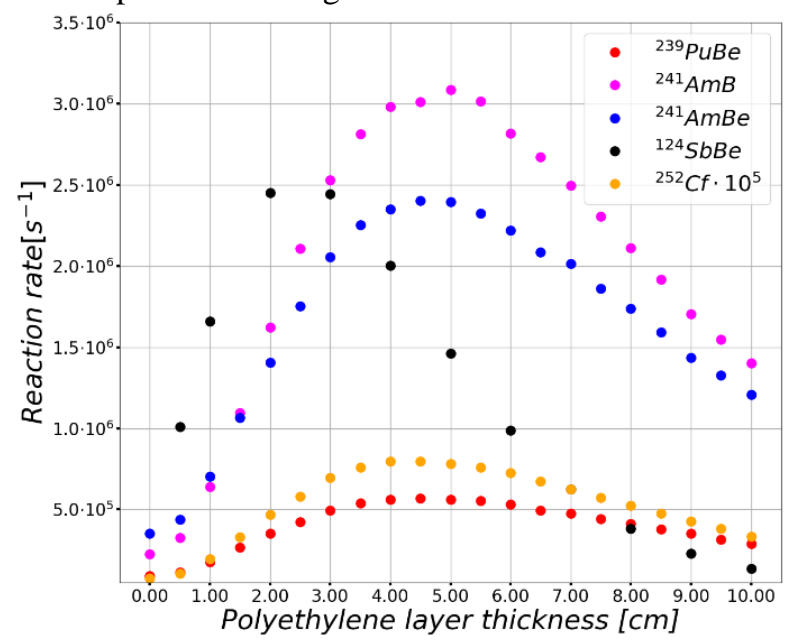

Fig. 3 - Fission reaction rates $\left({ }^{235} \mathrm{U} F \mathrm{FC}\right)$ induced by the neutron sources, depending on the polyethylene thickness (density $0.93 \mathrm{~g} / \mathrm{cm}^{3}$ ). (The maximum statistical uncertainty is $2 \sigma=3 \%$ ), calculated in SERPENT2 [10].

\section{Neutron detector}

Four detector types having high enough reaction cross-section with thermal neutrons [22] have been tested: A detector filled with ${ }^{3} \mathrm{He}$ gas, relying on a $(\mathrm{n}, \mathrm{p})$ reaction; A detector filled with $\mathrm{BF}_{3}$ gas, with $(n, \alpha)$ reaction on ${ }^{10} \mathrm{~B}$; A scintillator with ${ }^{6} \mathrm{Li}$, based on the $(n, \alpha)$ reaction; a fission chamber lined with ${ }^{235} U$. Some of the most important aspects of these detectors can be found in the Table 3.

Fig. 4 presents the results obtained for a ${ }^{239} \mathrm{PuBe}$ neutron source only. One can observe that signal in the detector with ${ }^{3} \mathrm{He}$ is the strongest (blue dots), whatever the selected neutron source, whereas the fission chamber (orange dots) records the lowest signal. Although the ${ }^{3} \mathrm{He}$ filled tube provides the highest response, it is significantly more sensitive to gamma radiation than ${ }^{10} \mathrm{~B}$ lined tube or fission chamber as it can be seen in the Table 3. This important criterion makes the choice of a fission chamber the most suitable.

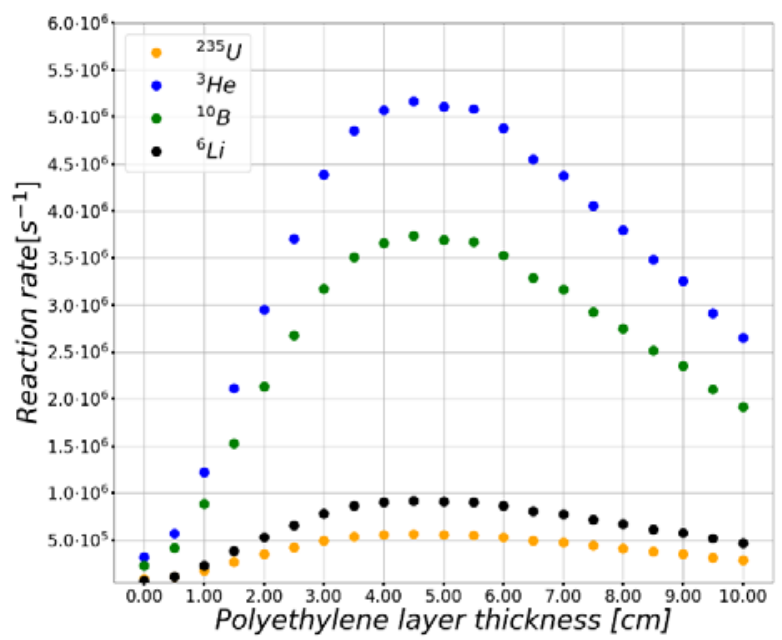

Fig. 4 - Microscopic reaction rates related to different detectors, using ${ }^{239} \mathrm{PuBe}$ neutron source, calculated in SERPENT2 [10].

TABLE 3 - PROPERTIES OF THE SELECTED THERMAL NEUTRON CONVERTER FOR NEUTRON DETECTION [18].

\begin{tabular}{rccc}
\hline \hline $\begin{array}{c}\text { Target } \\
\text { isotope }\end{array}$ & $\begin{array}{c}\text { Reaction } \\
\text { Type }\end{array}$ & $\begin{array}{c}\text { Reaction } \\
\text { cross-section } \mathrm{n}_{\text {th }} \\
{[\text { barn] }}\end{array}$ & $\begin{array}{c}\text { Maximum } \\
\text { equivalent rate } \\
{[\mathrm{Gy} / \mathrm{hr}]}\end{array}$ \\
\hline${ }^{10} \mathrm{~B}$ & $\mathrm{n}, \alpha$ & 3837 & $10^{-1}$ \\
${ }^{3} \mathrm{He}$ & $\mathrm{n}, \mathrm{p}$ & 5333 & $10^{-2}$ \\
${ }^{6} \mathrm{Li}$ & $\mathrm{n}, \alpha$ & 937 & $10^{-4}$ \\
${ }^{235} \mathrm{U}$ & $\mathrm{n}$, fiss & 582 & $10^{4}$ \\
\hline \hline
\end{tabular}

\section{Sensitivity of the setup to poisons concentration}

Irradiation time of the beryllium element affects the accumulation of ${ }^{6} \mathrm{Li}$ and ${ }^{3} \mathrm{He}$. The concentration of these isotopes determines the macroscopic absorption cross section of irradiated beryllium and thus the absorbed fraction of thermal neutrons incoming from the source.

As an example, Fig. 5 presents the difference between irradiated and nonirradiated beryllium, considering a fission chamber with ${ }^{235} \mathrm{U}$ deposit, a ${ }^{239} \mathrm{PuBe}$ neutron source and a variable polyethylene thickness.

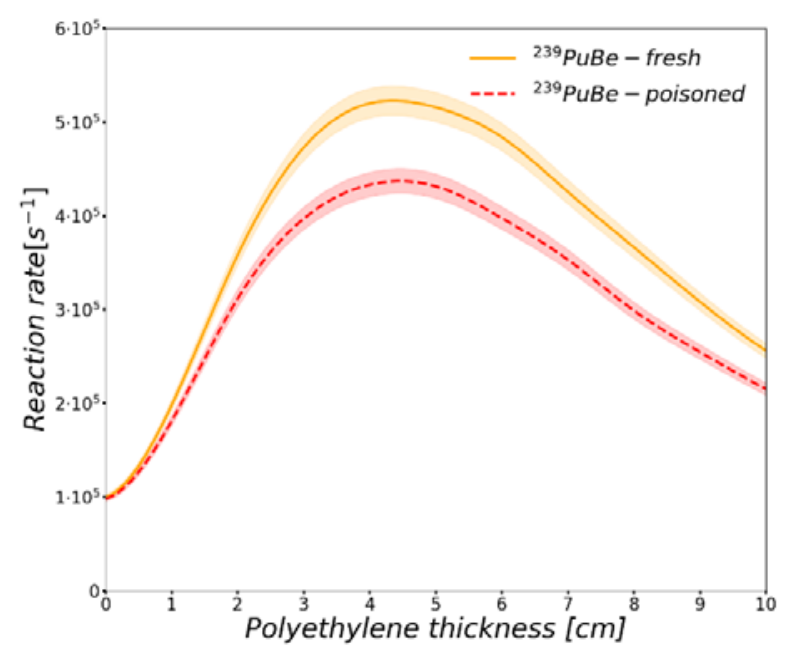

Fig. 5 - Comparison of reaction rates in fission chamber through irradiated and nonirradiated beryllium, using SbBe and PuBe neutron source with 3\% uncertainty marked, calculated in SERPENT2 [10]. 
The shaded area corresponds to the $2 \sigma$ uncertainty of about $3 \%$ resulting from the first campaign of experimental measurements performed in 2020 in the MARIA facility.

The accumulation of ${ }^{6} \mathrm{Li}$ and ${ }^{3} \mathrm{He}$ was calculated using an average neutron flux in beryllium element, calculated by a 3D full-core Monte-Carlo simulation of the MARIA reactor with the SERPENT2. Typical cycles of MARIA reactor have been considered, consisting of $100 \mathrm{~h}$ of reactor operation at nominal power, followed by an outage period of $68 \mathrm{~h}$ have been considered. The periods varied from 4 weeks to 14 years with 30 days of outage. The resulting poisons concentrations are presented in Table 4 and Fig. 6. Because these are analytically calculated values as described in [12], they do not contain uncertainties.

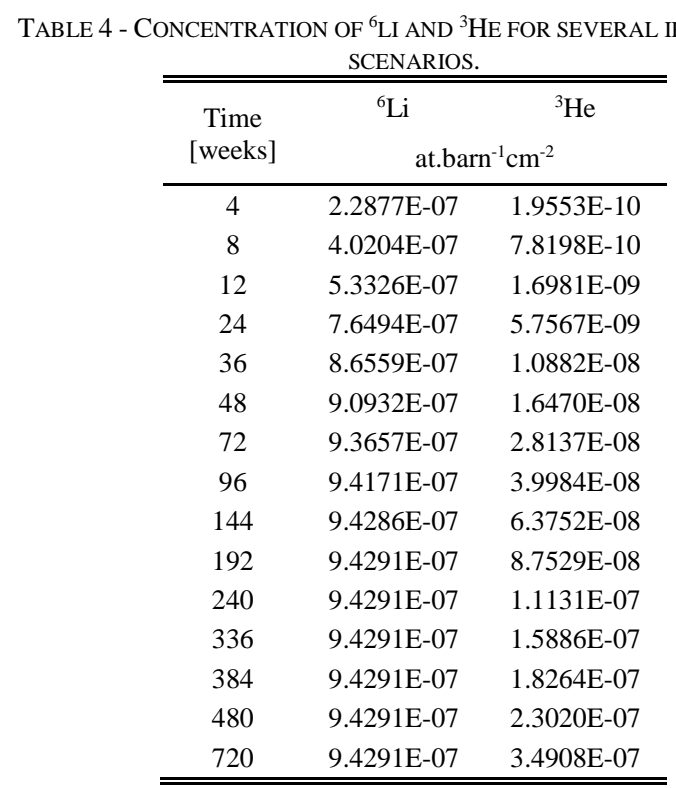

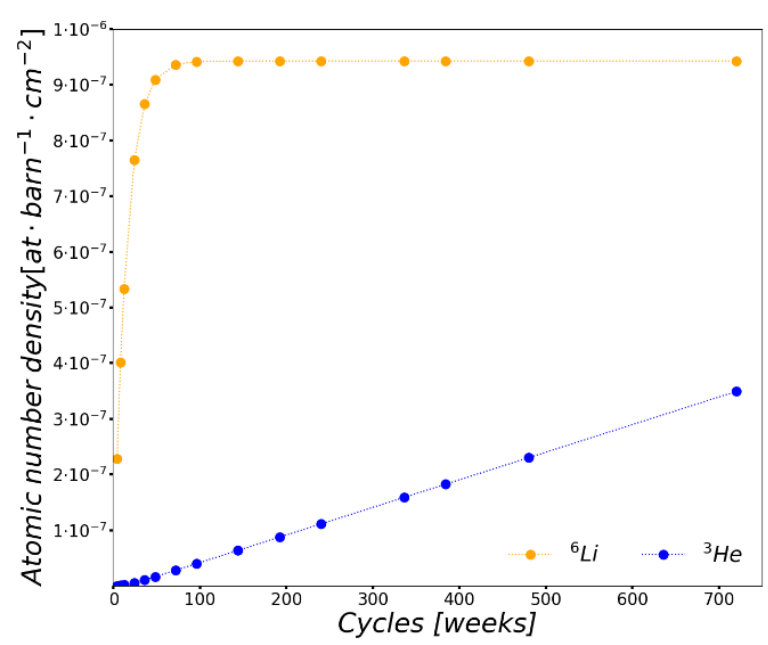

Fig. 6 - Accumulation of poisons for different irradiation scenarios .

Using SERPENT2 code, the detector's response was simulated for all neutron sources described in section A, depending on the poisons' concentration presented in the Table 4. Fig. 7 presents a percent difference between irradiated and nonirradiated beryllium element. One can observe that after the saturation of ${ }^{6} \mathrm{Li}$, the major impact on reactions induced in the detector has accumulation of ${ }^{3} \mathrm{He}$. The time needed to reach the minimum accumulation of poisons, will be thus very dependent on the overall outage time.

For all neutron sources, calculations were performed for the setup without polyethylene and the $4.5 \mathrm{~cm}$ thick polyethylene layer. In Fig. 7, the results of the simulations are presented with the $2 \sigma$ statistical uncertainty is $0.3 \%$.

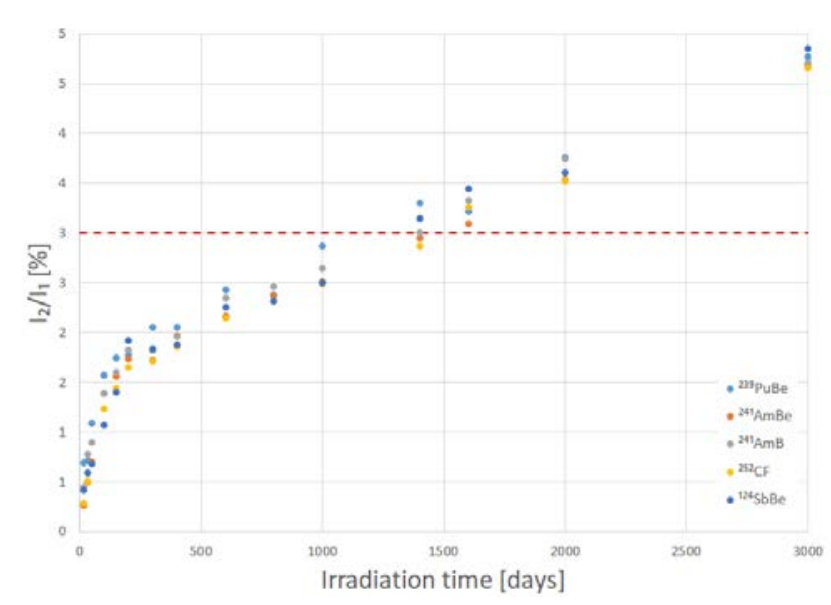

Fig. 7 - Comparison of fission chamber responses for studied sources and various amount of poisons.

Regardless of the chosen neutron source, the ratio of reaction rates between irradiated and nonirradiated beryllium is similar, so are the responses of other detectors. Taking into account all the above elements, the most suitable neutron source to be used in the measurements would be ${ }^{241} \mathrm{AmB}$.

\section{E. PuBe Neutron source uncertainties}

In the current configuration of the measurement setup, a PuBe neutron source is used. It is useful to examine the potential impact reported manufacturer's uncertainty of ${ }^{239} \mathrm{Pu}$ content [24] on the interpretation of the experimental results. The reaction rates in different detectors are calculated and presented in the Table 5 as a function of the fraction of the ${ }^{239} \mathrm{Pu}$ present in the neutron source. While increasing the ${ }^{239} \mathrm{Pu}$ concentration, the amount of other isotopes was decreased accordingly, by assuming a constant density of the source.

TABLE 5 - REACTION RATES FOR DIFFERENT DETECTORS, DEPENDING ON THE ${ }^{239}$ PU FRACTION IN THE ${ }^{239}$ PUBE NEUTRON SOURCE. MAXIMUM UNCERTAINTY

\begin{tabular}{ccccc}
\hline \hline $\begin{array}{c}{ }^{239} \mathrm{Pu} \\
\%\end{array}$ & $\mathrm{U}$ & $\mathrm{He}$ & $\mathrm{Li}$ & $\mathrm{B}$ \\
\hline 0.70 & $5.96 \mathrm{E}+05$ & $5.44 \mathrm{E}+06$ & $9.67 \mathrm{E}+05$ & $3.93 \mathrm{E}+06$ \\
0.85 & $5.94 \mathrm{E}+05$ & $5.42 \mathrm{E}+06$ & $9.65 \mathrm{E}+05$ & $3.92 \mathrm{E}+06$ \\
0.96 & $5.91 \mathrm{E}+05$ & $5.39 \mathrm{E}+06$ & $9.59 \mathrm{E}+05$ & $3.89 \mathrm{E}+06$ \\
\hline \hline
\end{tabular}

The impact of such variation of the ${ }^{239} \mathrm{Pu}$ content in the neutron source is restricted to the statistical uncertainty level. As can be 
seen in Fig. 8, the spectrum of PuBe neutron source simulated with iSourceC code differs in the intensity, thus with a properly measured emission rate of the used source, the impact of spectrum variation is negligible.

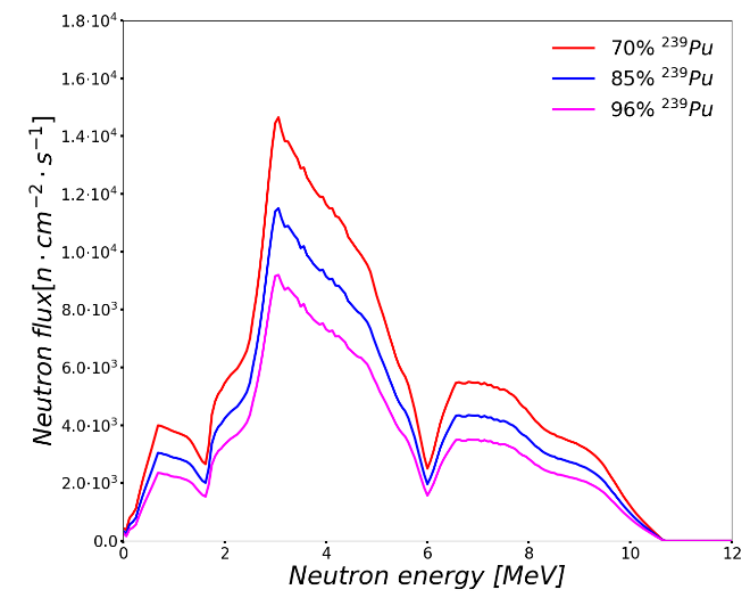

Fig. $8-{ }^{239} \mathrm{PuBe}$ neutron spectra depending on the ${ }^{239} \mathrm{Pu}$ content calculated with iSourceC program.

\section{CONCLUSIONS AND PERSPECTIVES}

The accumulation of thermal neutron absorbers in beryllium moderators and reflectors is an important problem in MTRs exploitation. An experimental method using neutron transmission has been developed to measure the concentration of these so-called poisons. This study presents a parametric analysis of the aforementioned setup, aiming to investigate experimental and numerical uncertainties associated with the method, as well as to optimize it.

Several neutron sources were considered, based on their characteristics. Two of them - ${ }^{241} \mathrm{AmB}$ and ${ }^{239} \mathrm{PuBe}$ are the most suitable for the experiment. These sources are characterized by low gamma emission and provide high counting rates. Depending on the reactor operation periods, a minimum of 1-3 years of irradiation time is needed to perform the measurements. Out of all investigated neutron detectors, fission chamber with ${ }^{235} \mathrm{U}$ deposit provides a safe choice for

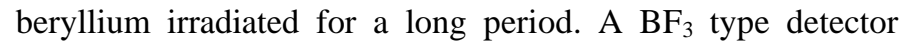
could be used alternatively if the gamma dose from beryllium activation is sufficiently low, because it provides higher sensitivity to thermal neutrons than the fission chamber.

The present study will be completed with gamma and uncertainty analysis whose results will be published in a companion paper. As the presence of several gamma sources in the measurement set affects the above choice, it is necessary to note that the two most important gamma sources would be the neutron source and activation of the impurities in beryllium element. The activity of the beryllium block used in the study [12] was measured at $\sim 10^{13} \mathrm{~Bq}$ for the entire block (that is about $1 \mathrm{GBq} / \mathrm{g})$. The uncertainties related to nuclear data should have some impact on the numerical analysis of the experiment, however further work is needed to perform full sensitivity analysis.

\section{REFERENCES}

[1] G.R. Longhurst, R.D. Rohe, Beryllium Use in Advanced Test Reactor. 8th IEA International Workshop on Beryllium Technology. INL/CON07-12959. Portugal. 2007.

[2] A. Gołąb, Aging management of beryllium and graphite blocks in research rector MARIA. National Centre for Nuclear Research, Poland. 2013.

[3] H. J. Stander et al., Replacement of the Core Beryllium Reflector in the SAFARI-1 Research Reactor. IAEA-TECDOC-1748. 2014. Web

[4] T.A. Tomberlin. Beryllium - A Unique Material in Nuclear Applications, article, November 1, 2004.

[5] A. Burkholtz, Irradiation damage in beryllium. Centre d'Etude de l'Energie Nucléaire. EUR3055.e. Belgium. 1966.

[6] S. Kalcheva, B. Ponsard, E. Koonen, Reactivity Effects due to Beryllium Poisoning of BR2. PHYSOR 2004. USA. 2004.

[7] V.V. Kalygin, A. P. Malkov, V.V. Pimenov, Effect of $3 \mathrm{He}$ and 6Li accumulation in beryllium blocks in the neutron-physical characteristics of the MIR reactor. Atomnaya Énergiya, Vol. 104, No. 2. Russian Federation. 2008.

[8] M. Wroblewska et al., Beryllium Poisoning for research reactors. European Research Reactor Conference. Rotterdam, Netherlands. 2017.

[9] M. Wroblewska et al., Qualification of Beryllium Poisoning Models for MARIA and Jules Horowitz Reactors. European Research Reactor Conference, Munich, Germany. 2018.

[10] J. Leppänen, et al. The Serpent Monte Carlo code: Status, development and applications in 2013. Ann. Nucl. Energy, 82 (2015) 142-150. 2015.

[11] A. Koning, R. Forrest, M. Kellett, R. Mills, H. Henriksson, Y. Rugama. The JEFF-3.1 Nuclear Data Library. Technical Report. JEFF Report 21, NEA - OECD. 2006.

[12] M. Wroblewska, D. Blanchet et.al. A review and analysis of the state of the art on beryllium poisoning in research reactors. Ann. of Nucl. Energy. (163)2021.

[13] H.R. Vega-Carrillo, S.A. Martinez-Ovalle. Neutron spectra and dosimetric features of Isotopic neutron sources: A review. ISSSD 2015 proceedings. Mexico. Sept. 2015.

[14] A. Wattenberg. Photo-Neutron sources. Physical Review. 71,497. 1947.

[15] IAEA. Neutron Monitoring for Radiological Protection. Technical Reports Series No: 252. IAEA. 1985.

[16] O.Bouland. Code iSourceC: Calcul de sources intrinsèques de neutrons. Private communication May 2021.

[17] IAEA. Compendium of Neutron Spectra and Detector Responses for Radiation Protection Purposes. Technical Reports Series No. 318. IAEA. 2001.

[18] D. Reilly, N. Ensslin, H. Jr. Smith, and S. Kreiner. Passive nondestructive assay of nuclear materials. United States. 1991. Web

[19] B.C. Anderson, K. E. Holbert, H. Bowler. Design, Construction, and Modeling of a 252Cf Neutron Irradiator.

[20] K.Pytel, J.Tombacher. Wymiana matrycy berylowej reaktora MARIA. IEA . Internal report [in polish] 1991.

[21] J.R. Granada, J. Dawidowski, R.E. Mayer, V.H. Gillette. Thermal neutron cross section and transport properties of polyethylene. Nuclear Instruments and Methods in Physics Research A261 Netherlands.1987.

[22] A. Oed. Detectors for thermal neutrons. Nuclear Instruments and Methods in Physics. Reas. Sec. A. Accelerators, Spectrometers, Detectors and Associated Equipment. 525(1). 2004.

[23] H.R. Vega-Carrillo, V.M. Hernández-Dávila, T. Rivera-Montalvo, A. Sánchez. Characterization of a 239PuBe Isotopic Neutron Source. Proccedings of the ISSSD 2012.

[24] J. Bagi, C.T. Nguyen, L. Lakosi, Assessment of the Pu content of $\mathrm{Pu}-$ Be neutron sources, Nucl. Instr. Meth. B222 (2004) 242-248. 